Vol. 3, No. 1, 2018

\title{
LINEAR ELECTROMECHANICAL GENERATOR IN THE CYBER-PHYSICAL SYSTEM OF SELECTION AND CONVERSION OF THE ARTILERY CANNON RECOIL ENERGY
}

\author{
Yuriy Shabatura, Maksim Balandin, Bohdan Seredyuk, Vitalii Atamanyuk \\ Hetman Petro Sahaidachnyi National Army Academy, 32, Gerois of Maydan str., Lviv, 79012, Ukraine. \\ Authors' e-mail: shabaturayuriy@gmail.com
}

Submitted on 01.12.2018

(C) Shabatura Yu., Balandin M., Seredyuk B., Atamanyuk V., 2018

\begin{abstract}
The current state and prospects of the development of cyber-physical systems for the conversion of energy of mechanical motion into electric energy have been analyzed; the design scheme of the mechanical energy conversion of the rolling parts of the artillery cannon into electrical energy has been developed; the initial characteristics of the linear generator have been analyzed; a mathematical model of the electromechanical converter has been outlined.
\end{abstract}

Index Terms: cyber-physical energy conversion system, linear generator, magnetic field, scattered energy.

\section{INTRODUCTION}

The present state of civilization is characterized, first of all, by the full penetration of computerization into all spheres and fields of human activity. Increasing computing capabilities along with micro-miniaturization leads to a wider application of artificial intelligence systems, their integration into artificial and natural technical and physical systems, and the creation of cyber-physical systems. Despite the incredible variety of all these systems, they retain a number of common features. In the first place, these are the principles of functioning, the radio-electronic basis for their implementation, and obligatory availability of the source of electricity. Considering the latter, it is worthwhile to discuss it in more detail, since no cyber-physiological system is able to function without power.

Cyber-physical systems of military use, depending on their purpose, have rather complicated architecture and are sorted into many types. However among them, in our opinion, the most promising are those systems that directly control and manage the means of fire damage. In order to ensure their uninterrupted functioning, it must be ensured that an affordable and reliable source of electrical energy is available.

As an example, in this paper, the principles, theoretical and applied aspects of the creation of autonomous power supply sources of cyber-physical systems of artillery units based on the use of energy scattered during artillery shots will be considered.

In the previous papers of the authors $[1,2]$ the issue of increasing the energy independence of artillery units through the recovery of energy dissipated during the shot of an artillery cannon was considered. It was determined that one of the main methods for obtaining useful types of energy is the transformation of the mechanical motion of the rolling parts of the artillery gun during the firing. It was also theoretically and practically substantiated that the most effective way to convert the reciprocating energy of the recoil parts of an artillery cannon is to use a linear generator on permanent magnets (LGPM).

The purpose of the work is to carry out an analysis of theoretical and practical aspects of the conversion of mechanical energy of the movement of rollback parts of an artillery gun during a shot into the electric energy and its subsequent use in cyber-physical systems. As well as the development of a mathematical model and design of a linear generator of the reciprocating motion on permanent magnets, determination of electromagnetic characteristics and energy efficiency of the proposed LGPM.

\section{PRESENTING THE MAIN MATERIAL}

At present, in order to provide power to cyberphysical systems there are many different ways of converting energy of motion, oscillation, vibrations into electric energy by means of devices based on the use of high-precision permanent magnets with high final magnetic induction $\mathrm{Br}$ (up to $1.5 \mathrm{~T}$ ). These devices are characterized by the stability of their own features at temperatures up to $400{ }^{\circ} \mathrm{C}$, as well as a small volume per unit of energy, resistant to the effects of demagnetization fields.

Consequently, electromechanical converters of cyber-physical systems on permanent magnets are not only competitive with their electromagnetic analogues, but also have functional advantages.

The main advantages of electric machines with excitation from permanent magnets are [3]:

1) the simplicity of the design due to the absence of the winding of excitation;

2) reduced overall dimensions and improved weight characteristics;

3) increased energy efficiency due to the absence of loss of excitation; 
4) increased reliability;

5) the stability of the magnetic flux - its independence on fluctuations in temperature, network voltage, frequency of rotation;

6) improved cooling conditions.

One of the subspecies of contactless electric machines is linear motors (generators) with excitation from permanent magnets.

In view of the obvious advantages over rotor motors, linear motors have received a fairly limited application. The reason for this is their low power, due to the small size of the moving part (rotor), which prevents the placing of more powerful permanent magnets (PM) of large size and relatively little span of rotor motion (amplitude of oscillation).

At present, power electromechanical converters of cyber-physical systems with high-precision permanent magnets are used in virtually all industries. For a generalized analysis in order to choose the optimal design of LGPM there is a need to outline their classification.

Linear generators can be classified:

1) by purpose:

- measuring generator;

- power transformer.

2) by the principle of operation:

- DC generators;

- alternators.

3 ) by the nature of the motion:

- translational;

- reciprocating.

4) by constructive execution:

- flat shape;

- cylindrical shape;

- a multifaceted form.

5) by the design of the moving part:

- with a movable winding (stator with PM);

- with a moving magnetic core;

- with a moving rotor.

Considering the fact that constructively, as proposed in $[1,2]$ the LGPM is supposed to be installed on the existing model of armament, so the final version of its implementation depends on the features of the design of the artillery system.

The greatest advantage of the proposed approach is that the use of LGPM allows, without any mechanical connections, to directly convert the translational motion of the recoil parts of the gun into electrical energy.

The proposed construction of LGPM cyber-physical system is shown in Fig. 1. It consists of a movable rotor 1 , the basis of which is the band 2 fixed to the barrel of the gun 3 together with the magnetic core 4 and the pairs of permanent magnets 5 , the stator 6 , which is stationary mounted on the gun 7 , surrounded by the inductive coils 8 .

It should be noted that the gun barrel has a tapered shape, and the rope band is cylindrical, which leads to the creation of a gap between the barrel and the bandage, which will act as a diamagnetic seal and will reduce the heating temperature of the rotor, which is a significant factor, since permanent magnets have a certain range of operating temperatures and lose magnetic properties when exceeding a certain critical temperature value.

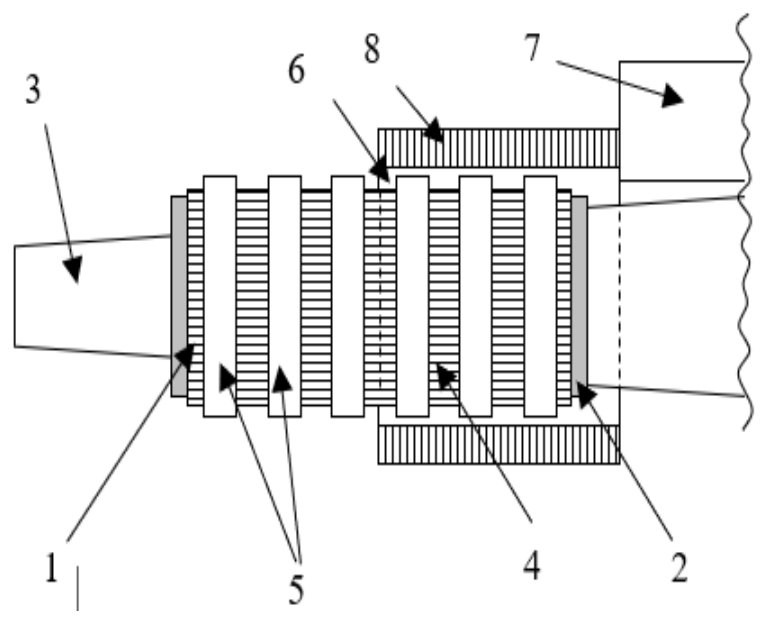

Fig. 1. Construction of a linear generator on permanent magnets (LGPM)

The proposed generator works as follows. During the shot, the rollback parts of the gun under the action of jet forces move to the rear position (the phenomenon of recoil force). Alongside with them, the rotor in the middle of a stationary stator is moved and fixed to the barrel, due to which, according to the law of electromagnetic induction, the induction coils of the stator are driven by an electromotive force which magnitude depends on the velocity of the rotor, the number of turns in the coils, and the magnitude of the magnetic flux permeating the coil $[4,5]$.

The motion of the rollback parts has a pulse form and lasts a very short time. For example, when shooting at maximum charge with a high explosive shell of $122 \mathrm{~mm}$ howitzers M-30, the speed of recoil at the moment of the greatest pressure of the powder gases is $5.17 \mathrm{~m} / \mathrm{s}$; the speed of recoil at the moment of departure of the projectile from the canal of the barrel $-12.33 \mathrm{~m} / \mathrm{s}$; length of recoil $-0.816 \mathrm{~m}$; rollback time $-0.155 \mathrm{sec}$.

An important feature of the movement of rollback parts is that the workflow during which the conversion of mechanical energy into electrical energy takes place is solely due to recoil. The motion of these parts aimed at returning to the initial state must be carried out freely without any braking effects from the LGPM system.

The magnitude of the magnetic flux in a certain area of space above the magnet depends on the characteristics of the permanent magnet - the residual magnetic induction $\mathrm{Br}$, the coercive force $\mathrm{Hc}$, the magnetic energy $\mathrm{kJ} / \mathrm{m}^{3}$, the shape and size (volume) of the permanent magnets, and the method of placement of permanent magnets.

There are three options for excitation of magnetoelectric linear generators (arrows show the direction of the magnetic flux) [6]: 
(Fig. 2);

- with axially magnetized permanent magnets

- with radially magnetized permanent magnets (Fig. 3);

- with radial-tangential placement of permanent magnets, which has alternate magnetization - the configuration of Halbach (Fig. 4).

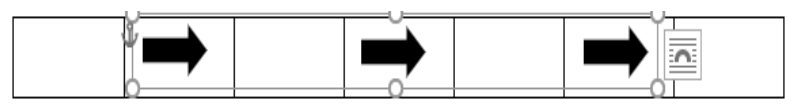

Fig. 2. Scheme of the magnetization system of the inductor with axially magnetized magnets

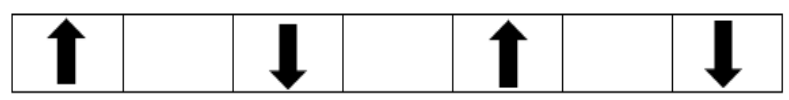

Fig. 3. Scheme of the magnetization system of the inductor by radially magnetized magnets

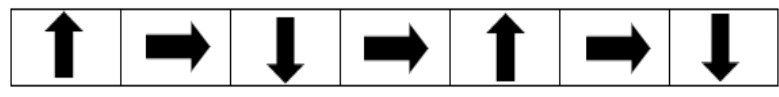

Fig. 4. Scheme of the magnetization system of the inductor by radially magnetized magnets

An analysis of the research has shown that the Halbach magnetization option is optimal in terms of obtaining the largest flow and mass-size indicators. At the same time, this option is the most cost-effective in terms of the use of magnetic materials. Therefore, in the proposed version of the LGPM design, a magnetization system with radially magnetized permanent magnets was chosen.

To obtain the required value of the active electromotive force (EMF) and maximum generator power, a constant electromagnetic interaction between the rotor and the stator is required. It is structurally possible to have two cases to carry out this task:

- using a double length of the stator;

- using a double rotor length.

Taking into account the possibilities of placing on an artillery gun, and considering the design of a selected type of linear generator with a moving rotor, it is advisable to choose an option with a doubled rotor length, that is, the one with the increased length of the active site containing permanent magnets.

On the basis of the conducted research it was established that the most promising converter of mechanical energy of the movement of rollback parts into electric energy is a single-phase cylindrical linear generator of translational motion, impulse action, with a moving rotor.

Proceeding from the fact that the bandage of LGPM, which is fixed to the gun barrel, has a cylindrical shape, it is advisable to choose the segmental shape of the permanent magnets that will be formed in the ring for the active part of the rotor. To increase the reliability of the generator, and to protect permanent magnets from mechanical damage, it is possible to install the protective case from the diamagnetic material on the active part of the rotor.

The task of LGPM design consists in the right selection of the main dimensions, calculating the power of the generator, determining the electromagnetic and thermal loads, selecting the magnetic system and the size of permanent magnets as well as conducting economic calculations.

Let's consider consecutively the above mentioned components.

The choice of the main dimensions.

Due to the fact that the generator of cyber-physical system is planned to be integrated into the artillery complex, the choice of the main dimensions of the LGPM is dictated by the design features of the cannon. That is, the possibilities of placing LGPM on a gun are limited by the overall dimensions (outer diameter) of the gun barrel, and the length of recoil, which in LGPM will be the range of motion of its active section.

For example, the outer diameter of the barrel is $122 \mathrm{~mm}$ for howitzers D-30, in a place where the stationary fixing of the stator LGPM is possible, is $200-178 \mathrm{~mm}$, and the rollback length reaches $740-930 \mathrm{~mm}$. That is, the placement of LGPM with an inner diameter of $200 \mathrm{~mm}$ and an active site length of $740 \mathrm{~mm}$ is possible.

The generated power is estimated based on the fact that the formation of recoil energy goes up to $5 \%$ of the energy of the powder gases. Since this process is rapid (its duration is $\mathrm{t} \approx 0.15 \mathrm{~s}$ ) then impulse releases of capacities from 6 to $100 \mathrm{MW}$ depending on the caliber as well as the power of the charge and the characteristics of the gun will be observed.

Determination of electromagnetic loads consists in the calculation of electromagnetic characteristics of LGPM, in order to obtain a given value of EMF. The initial data for such calculations are the characteristics of the receiver of electric energy, which source of power will be the projected LGPM. Due to the fact that the electric current obtained from LGPM will have a pulse form, therefore, for the accumulation and temporary conservation of energy, only a special capacitor capable of absorbing high-energy electrical impulses can be used. A supercapacitor battery is chosen as such a capacitor. The table below lists the characteristics of the Maxwell supercapacitor modules available from the source [7].

To perform calculations of the electromagnetic characteristics of the proposed LGPM it is necessary to complete the synthesis of the corresponding mathematical model.

According to $[8,9]$ the output voltage of the investigated generator will be determined by the formula:

$$
U=B \cdot L \cdot V_{r} \cdot \sin \alpha
$$

where, $B$-average magnetic induction in the loops of the coil; $L$ - active length of the coil conductor; $V r-$ speed of the rotor motion; $\alpha$ is the angle between the direction of the magnetic field strength lines of the 
permanent magnets and the plane in which the coils of the generator are located.

Magnetic induction in the working gap for cylindrical magnets is calculated by the formula [7]:

$$
\begin{gathered}
B=B_{r}\left(1-\frac{2 g-k_{c}+h}{D}\right) \frac{1}{1+\mu_{r}-\left(\frac{g-k_{c}}{\tau}\right)\left(1-\frac{2 g-k c+h}{D}\right)} \\
\frac{1}{\left(1+k_{f}\right)\left(1+k_{s}\right)} .
\end{gathered}
$$

whereas, $\mathrm{Br}$ - final induction; $\mathrm{g}$ - the thickness of the air gap between the stator and the rotor; $\mu_{r}$ - magnetic permeability of magnetic material; $k_{c}-$ Carter coefficient, total air gap coefficient; $k_{s}$ - coefficient of magnetic saturation; $k_{f}$ - permanent magnets balance ratio; $h$ - height of the permanent magnet; $\tau$ - pole section of the permanent magnet; $D$ - inner diameter of the stator.

The experience of designing cylindrical linear electric machines on permanent magnets shows that it is advisable to choose the above coefficients in the following range:

$$
k_{c}=1.05 \div 1.25, k_{s}=0.10 \div 0.25, k_{f}=0.1 \div 0.2 \text {. }
$$

The value of the density of the magnetic induction at a given distance $\Delta$ from the ring of permanent magnets within the stator LGPM can be calculated using the formula:

$$
B_{\Delta}={\frac{1}{\Delta_{1}}}^{g} B(\Delta) d \Delta
$$

where, $\Delta-$ the height of the working gap of the LGPM which consists of the sum of the air gap $\delta$, the average value of the $h_{s t}$ thickness and the thickness of the bandage wall $h_{b}$ :

$$
\Delta=\delta+h_{s t}+h_{b}
$$

The active length of the stator coil conductor is part of the coil which is affected by the magnetic fields of permanent magnetic generators. It is calculated by the formula:

$$
L=l \cdot N \text {. }
$$

where, $l$ - average coil length of the stator; $N$ - number of turns in the coil of the stator.

The average length of the turn is calculated by the formula:

$$
l=\pi d .
$$

Hence: $L=N \cdot \pi \cdot d$.

Since the LGPM design implies the constant value of the angle $\alpha=90^{\circ}$ for all modes of operation, as well as the stability of other structural parameters, the dynamics of the change in the energy characteristics will be determined by the changes in rotor velocity.

The conducted experimental studies allowed estimating the patterns of the motion of the rolling parts of the gun. In piecewise-linear approximation, the dependence of the speed of motion of the recoil parts of the gun, and hence, the rotor motion in the process of the shot, is outlined in Fig. 5.

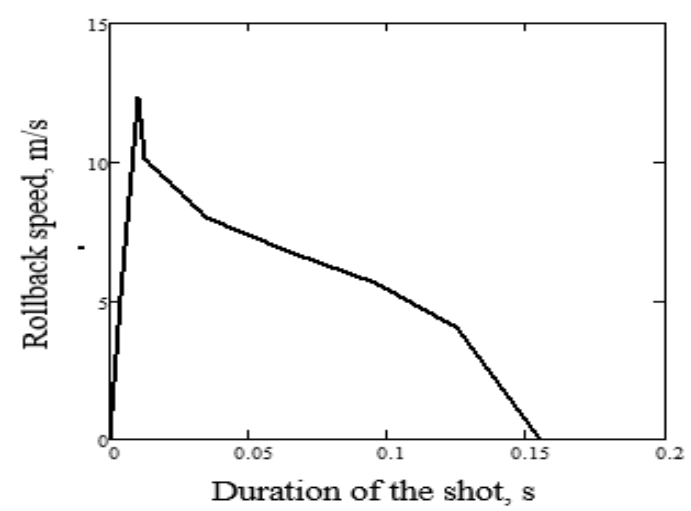

Fig. 5. Dependence of the speed of motion of recoil parts on the duration of the shot

From figure 2, it can be seen that the energy characteristics of the LGPM of the cyber-physical system will be variable, and the maximum value of the generated voltage will be reached at the point of maximum speed of the rollback parts.

Since in order to obtain a mathematical model of LGPM it is necessary to have an analytical continuously differentiated function for determining the speed of rollback parts during the firing process, so special studies have been carried out in the Maple system, which allowed to obtain the specified function in the form of the following equation:

$$
\begin{aligned}
V(t)= & \frac{t}{0.001-0.152 t+17.518 t^{2}-506.254 t^{3}+7716693 t^{4}} \\
& \frac{t}{-57875.022 t^{5}+170588.883 t^{6}}
\end{aligned}
$$

Table 1

Characteristics of supercapacitors batteries

\begin{tabular}{|c|c|c|c|c|c|c|}
\hline Model & $\begin{array}{c}\text { Nominal } \\
\text { capacity, } \\
\mathrm{F}\end{array}$ & $\begin{array}{c}\text { Voltage, } \\
\mathrm{V}\end{array}$ & $\begin{array}{c}\text { Max. Current, } \\
\mathrm{A}\end{array}$ & $\begin{array}{c}\text { Stored Energy, } \\
\mathrm{W}\end{array}$ & $\begin{array}{c}\text { Number of } \\
\text { sections, } \\
\text { pcs. }\end{array}$ & $\begin{array}{c}\text { Weight, } \\
\mathrm{kg}\end{array}$ \\
\hline BMOD0165 P048 C01 & 165 & 48 & 1900 & 53 & 18 & 14.2 \\
\hline BMOD0006 E160 B02 & 5,8 & 160 & 170 & $60 \times 0.35$ & 60 & 5.2 \\
\hline BMOD0189 P051 B2A & 189 & 51 & 1900 & 69 & 18 & 16.8 \\
\hline BMOD0165 P048 C01 & 58 & 16 & 170 & $6 \times 0.35$ & 6 & 0.63 \\
\hline BMOD0165 P048 BXX & 165 & 48 & 1900 & $18 \times 3$ & 18 & 13.5 \\
\hline BMOD0083 P048 B01 & 83 & 48 & 1150 & $18 \times 1.5$ & 18 & 10.3 \\
\hline
\end{tabular}


Considering that the output voltage of the LGPM should not exceed the permissible voltage of the supercapacitor battery Umax, therefore, based on equations (1) and (5), the formula for determining the number of turns in the stator induction coils can be obtained:

$$
N=\frac{U_{\max }}{B \cdot l \cdot V_{r_{\max }}} .
$$

In order to ensure that the supercapacitor battery is efficiently charged, it is necessary that the LGPM provides a high value of the pulse charging current $\mathrm{I}_{\max }$, which at the same time should not exceed the maximum permissible charging current of the selected supercapacitor $\mathrm{I}_{\mathrm{Cmax}}$, that is:

$$
I_{\max } \mathrm{p} I_{C \max }
$$

Thus, based on known parameters of the supercapacitor battery, we can obtain the calculated formula for determining the allowed resistance of the stator induction coils:

$$
R_{k}=\frac{U_{\max }}{I_{\max }}-r .
$$

where, $r$ - internal resistance of the supercapacitor module.

On the other hand, taking into account the cylindrical geometry of induction coils, their resistance will be determined from the ratio:

$$
R_{k}=N \frac{\rho_{\mathrm{T}^{\circ} \mathrm{C}} \cdot l}{S} .
$$

where, $S$ - cross sectional area of the uninsulated wire of the coil;

$\rho_{T^{\circ} \mathrm{C}}$ - the specific electrical resistance of copper.

$$
\rho_{T^{\circ} \mathrm{C}}=\rho_{T 20^{\circ} \mathrm{C}} \cdot\left(1+\alpha\left(T_{\max }-20\right) .\right.
$$

where, $\alpha=0,004 ; T$ - operating temperature for which the resistivity is calculated; $\rho_{T 20^{\circ} \mathrm{C}}-$ specific electrical resistance of copper at $20^{\circ} \mathrm{C}$.

The expression for calculating the required crosssectional area of the uninsulated wire can be obtained from equation (11):

$$
S=N \cdot \frac{\rho_{T^{\circ} C} \cdot l}{R_{k}} .
$$

In addition to the electrical calculation, it is necessary to carry out a thermal calculation of stator coils taking into account the pulsed nature of the current flowing through them. For this a well-known Onderdock formula can be used:

$$
8.610^{-6}\left(\frac{I}{S}\right) t=\lg \left[\left(1+\frac{\Delta T}{234+T_{0}}\right)\right] .
$$

where, $\mathrm{t}$ - time of current passing through a copper conductor, which is determined by the duration of the shot; $\Delta \mathrm{T}$ - increase in temperature relative to the initial temperature; $\mathrm{T}_{0}$ - the initial temperature.

So, using formula (14) the expression for calculating the minimum value of the cross-sectional area of the coil wire based on the conditions of the permissible thermal regime can be obtained:

$$
S_{\partial}=\sqrt{\frac{8.610^{-6} \cdot I^{2} \cdot t}{\lg \left[\left(1+\frac{\Delta T}{234+T_{0}}\right)\right]}} .
$$

As experimental studies have shown, for further calculations it is necessary to use the previously determined value $S$, if condition $S>S_{\partial}$ is fulfilled.

In addition to the electrical and thermal calculations, it is necessary to perform and force calculation, because in the conditions of large currents passing through the coil turns the coils will be subjected to a significant Ampere force. Since the coils are located in a nonmagnetic medium, then this force will be determined by the formula [11]:

$$
F_{a}=2 p \cdot m \cdot B \cdot l \cdot N \cdot I_{\max } .
$$

where, $p$ - the number of magnetic pole pairs; $m$ number of coils.

Obviously, the mounting of the stator coils should have sufficient strength to counteract this force.

According to the known dimensions and characteristics of permanent magnets, a magnetic flux when operating in idle mode is as follows:

$$
\Phi_{0}=p \cdot B \cdot S_{m} \cdot \sigma_{0} \cdot
$$

where, $p$ - the number of magnetic pole pairs; $S_{m}-$ surface area of the magnet under the coils; $\sigma_{0}-$ coefficient of scattering.

When selecting the geometric parameters of a magnetic system, the value of the scatter coefficient can be taken in the range $\sigma_{0}=0,35 \div 0,45$.

The total electric power that is produced by the generator in the process of a single shot will be determined by the formula:

$$
P_{f}=\int_{t=0}^{t_{\text {shot }}} U(t) \cdot I(t) d t,
$$

Instantaneous maximum power of LGPM:

$$
P_{\max }=I_{\max } \cdot U_{\max } \cdot
$$

Direct electric losses in the generator's coils:

$$
P_{l}=m \cdot R_{k} \int_{t=0}^{t_{\text {shot }}} I^{2}(t) d t
$$

Taking into account the above analytic dependences for parameters and characteristics of LGPM, after substituting them into formula (1) we obtain a generalized mathematical model of LGPM:

$$
\begin{gathered}
U\left(V_{r}\right)=B_{r}\left(1-\frac{2 g-k_{c}+h}{D}\right) \frac{1}{1+\mu_{r}\left(\frac{g-k_{c}}{\tau}\right)\left(1-\frac{2 g-k c+h}{D}\right)} \\
\cdot \frac{1}{\left(1+k_{f}\right)\left(1+k_{s}\right)}\left(\frac{t \cdot N \cdot(d \cdot \pi) \cdot \sin \alpha}{0.001-0.152 t+17.518 t^{2}-506.254 t^{3}} .\right.
\end{gathered}
$$

\section{$\left.+7716693 t^{4}-57875.022 t^{5}+170588.883 t^{6}\right)$}

In order to check the obtained theoretical results, we perform calculations of the main characteristics of LGPM cyber-physical system for $122 \mathrm{~mm}$ howitzers D-30. 
Table 2 determine the average length of the coil single turn

\section{Output data for calculations}

\begin{tabular}{|l|c|c|}
\hline \multicolumn{3}{|c|}{ Structural characteristics } \\
\hline Outer diameter of the rope tire & $\mathrm{D}$ & $200 \mathrm{~mm}$ \\
\hline $\begin{array}{l}\text { The height of the magnetic circuit of the } \\
\text { rotor }\end{array}$ & $\mathrm{h}_{\mathrm{mp}}$ & $5 \mathrm{~mm}$ \\
\hline Magnet Height & $\mathrm{h}$ & $15 \mathrm{~mm}$ \\
\hline Air gap & $\delta$ & $1 \mathrm{~mm}$ \\
\hline Magnet Width & $\mathrm{b}_{\mathrm{M}}$ & $60 \mathrm{~mm}$ \\
\hline Polar section of the magnet & $\tau$ & $120 \mathrm{~mm}$ \\
\hline Height of the stator & $\mathrm{h}_{\mathrm{st}}$ & $3 \mathrm{~mm}$ \\
\hline \multicolumn{3}{|c|}{ Characteristics of a permanent magnet } \\
\hline Final induction & $\mathrm{B}_{\mathrm{r}}$ & $1.25 \mathrm{~T}$ \\
\hline Coercive force be-B brand 38EN & $\mathrm{H}_{\mathrm{c}}$ & $907 \mathrm{kA} / \mathrm{m}$ \\
\hline Operating temperature & $\mathrm{T}_{\mathrm{po \sigma}}$ & $200{ }^{\circ} \mathrm{C}$ \\
\hline \multicolumn{2}{|c|}{ BMOD0189 P051 B2A Supercapacitor Battery } \\
\hline Specifications & $\mathrm{Umax}$ & $54 \mathrm{~V}$ \\
\hline Operating voltage & $\mathrm{U}$ & $51 \mathrm{~V}$ \\
\hline Maximum current & $\mathrm{I}_{\max }$ & $1900 \mathrm{~A}$ \\
\hline Capacity & $\mathrm{C}$ & $189 \mathrm{~F}$ \\
\hline Internal resistance & $\mathrm{r}$ & $0.0056 \mathrm{Ohm}$ \\
\hline
\end{tabular}

Below the calculation of the magnetic induction in the air gap is outlined by the formula (2).

The dependence of magnetic induction on the gap $\Delta$ is shown in Fig. 6.

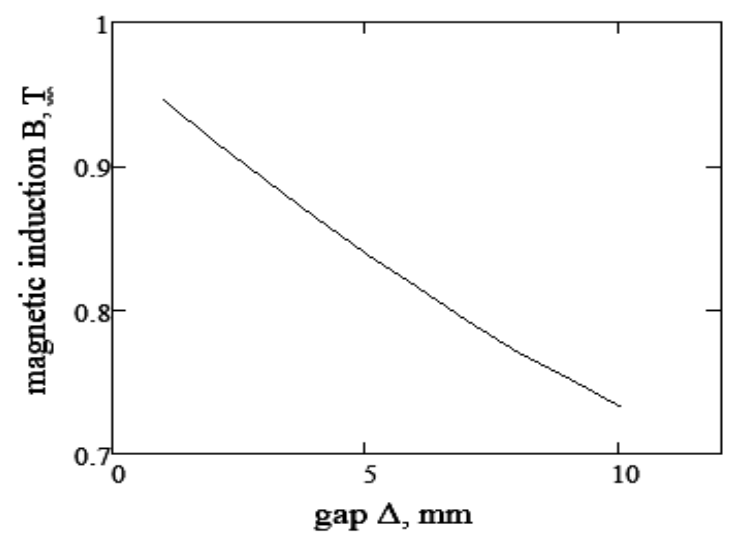

Fig. 6. Distribution of magnetic induction in the working range of the stator

The height of the working gap of the LGPM will be an application of the height of the air gap, the height of the stator and the thickness of the wall of the stator's band:

$$
\Delta=\delta+h_{s t}+h_{b}=5 \mathrm{~mm},
$$

The average magnetic induction in the working gap will be:

$$
B_{\delta}(\Delta)=0.885 T
$$

Taking into account the geometric dimensions of the rotor, permanent magnets, the magnetic conductor and working gaps, the calculations made allowed to $l=0,785 \mathrm{~m}$.

The calculation performed by formula (8) allowed to determine the required number of coil turns $N=6$.

The value of the resistance of the induction coil for a charge current of $1500 \mathrm{~A}$, a maximum voltage of $51 \mathrm{~V}$, and an internal resistance of the supercapacitor battery of $0.0056 \mathrm{Ohm}$ according to the formula (10):

$$
R_{k}=0.040 \mathrm{hm} \text {. }
$$

By formula (13) we find the cross-sectional area for the operating temperature of $95{ }^{\circ} \mathrm{C}$, the known average length of the single turn and the number of turns in the coil:

$$
S_{m}=2.645 \mathrm{~mm}^{2}
$$

Checking the match between the selected wire with thermal load using the Onderdock formula for a pulsed current gives the value:

$$
S_{\partial}=5.166 \mathrm{~mm}^{2}
$$

In this way, it becomes obvious that the calculated cross-sectional area is less than the thermal permissible value. Therefore, we finally choose the wire - a rectangular wire $2 \times 3 \mathrm{~mm}, \mathrm{~S}=6 \mathrm{~mm}^{2}$.

Using the calculated mean value of the induction in the working gap, and the change in the speed of the rotor, the energy characteristics of the LGPM of the cyber-physical system have been calculated. The results of calculations are summarized in Table 3.

Table 3

Energetic characteristics of LGPM

\begin{tabular}{|c|c|c|c|c|}
\hline $\begin{array}{c}\text { Duration } \\
\text { of the } \\
\text { shot } \\
\mathrm{s}\end{array}$ & \multirow{2}{*}{$\begin{array}{c}\text { Rotor's } \\
\text { velocity } \\
\mathrm{m} / \mathrm{s}\end{array}$} & $\begin{array}{c}\text { Voltage } \\
\mathrm{V}\end{array}$ & $\begin{array}{c}\mathrm{T}=20^{\circ} \\
\mathrm{R}=0.013\end{array}$ & $\begin{array}{c}\mathrm{T}=95^{\circ} \\
\mathrm{R}=0.017\end{array}$ \\
\hline 0.004 & 6.232 & 23.237 & 1221 & 1008 \\
\hline 0.01 & 12.546 & 46.775 & 2458 & 2028 \\
\hline 0.012 & 12.372 & 46.129 & 2424 & 2000 \\
\hline 0.024 & 9.317 & 34.738 & 1825 & 1506 \\
\hline 0.034 & 8.23 & 30.686 & 1612 & 1331 \\
\hline 0.065 & 6.796 & 25.336 & 1331 & 1099 \\
\hline 0.095 & 5.684 & 21.193 & 1114 & 919.082 \\
\hline 0.125 & 3.527 & 13.151 & 691.038 & 570.295 \\
\hline 0.155 & 1.001 & 3.731 & 196.033 & 161.781 \\
\hline $\begin{array}{c}\text { average } \\
\text { value }\end{array}$ & $\mathbf{7 . 3}$ & $\mathbf{2 7 . 2 2}$ & $\mathbf{1 4 3 0 . 2 3}$ & $\mathbf{1 1 8 0 . 3 5 1}$ \\
\hline
\end{tabular}

The average instantaneous power that is released on one coil will be:

$$
P=38.930 k W
$$

\section{CONCLSIONS}

The theoretical studies carried out in this paper have been accompanied by the use of experimental data and allowed to obtain a sequence of analytical models and an algorithm for their application for the design calculation of LGPM cyber-physical systems that can be installed for the control and management of firearms. 
In order to test the theoretical results and evaluate the energy characteristics of LGPM, the calculation of the specified generator for the howitzer system has been performed. The results of the calculations showed the high energy efficiency of the proposed generator. Moreover, the lack of mechanical contacts indicates high reliability of the functioning of such a generator and hence the cyber-physical system as a whole.

\section{REFERENCES}

[1] Shabatura Yu. V., Balandin M. V. Pidvishennya boyovih mozhlivostey artileriyskogo pidrozdilu za rahunok zastosuvannya alternativnih dgherel zhivlennya [Increating the ambitios opportunities of the artillersc division by the account of alternative sources of nutrion]. Zhytimyr military institute journal. Zhitomir, Ukraine, 2017, vol. 14. pp. 31-41 (In Ukrainian).

[2] Shabatura Yu. V., Balandin M. V. Analiz I ocinka efektivnosti metodiv I zasobiv vidboru ta peretvorennya rozsiuvanoi energii, yaka vudilyaetsya $\mathrm{v}$ procesi postrilu artileriyskoi garmati. [Analysis and evaluation of the effectiveness of methods and means of selection and conversion of dissipated energy released during the firing of artillery guns]. Military-technical journal of Lviv National academy of land forces. Lviv, Ukraine, 2018. vol.18. - pp.52-61. (In Ukrainian).

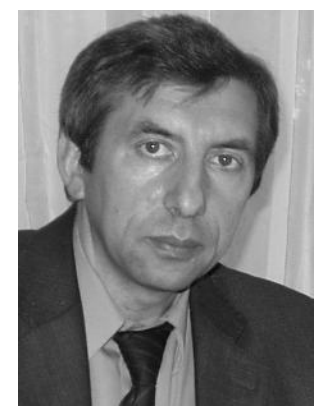

Professor Yuriy Shabatura is the head of the Chair of Electromechanics and Electronics at the National Academy of Land Forces named after Hetman Petro Sahaidachnyi. He has graduated from the Vinnytsia Polytechnic Institute in 1985. In 1992 he received a Candidate of Technical Sciences degree at Kyiv Polytechnic Institute. In 2008, he received a Doctor of Technical Sciences (Ph.D.) degree at Vinnytsia National Technical University, specializing in computer systems and components. $\mathrm{He}$ is the author of more than 400 scientific publications, including 52 patents, 2 monographs, many articles in periodicals and specialized publications. His scientific interests lie in the field of development and research of informationmeasuring, managing and controlling systems.

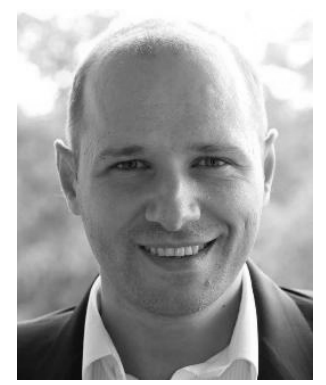

Bohdan Seredyuk was born in 1980 in Lviv. In 2002 he has graduated from Ivan Franko Lviv National University and obtained specialty "Physicist". At present he is a professor at the department of Rocket Troops and Artillery, chair of Electromechanics and Electronics of the Hetman Petro Sahaidachnyi National Army Academy. He has been involved in scientific work since 2004. The aspect of his research is magnetic sensors based on semiconductor structures for military implications.
[3] Ismagilov F. R. Electromechanical systems with high coercive permamnent magnets - Moscow: Mashynostrojenije, 2014. 267 p. (In Russian).

[4] Patent. 110392 Ukraine, МПКH02N2/18F03G3/00. A method and device for obtaining electric energy based on the use of energy dissipation from a cannon shot. Yu. V. Shabatura, M. V. Balandin, published. 25.12.2015, Bull. vol.24. (In Ukrainian).

[5] B. O. Seredyuk, R. W. McCullough, H. B. Gilbody. Collision mechanisms in one-electron capture by $\mathrm{He}^{2+}$ ions in collisions with hydrocarbons. Phys. Rev. A. - 2005. - Vol. 71.P. 022713-1-022713-5.

[6] Sergeenkova E. V. Synchronous electric machine of the reciprocating motion (generator): $\mathrm{PhD}$ thesis: 05.09.01 Moscow, 2011. - 118 p. (In Russian).

[7] Ultracapacitor Modules. maxwell Technolgies. - 2018. Resource access URL: http://www.maxwell.com/products/ ultracapacitor /modules.

[8] Tarashev S. A. Valve linear generator for power systems of autonomous objects: PhD thesis: 05.09.01, Samara, 2011. 129 p. (In Russian).

[9] Flora V. D. Electric machines of special designs and principles of operation - Zaporizhya: Information system iElectro, 2011. 254 p. (In Ukrainian).

[10] Boldea I. Linear Electric Machines, Drives, and MAGLEVs Handbook / Ion Boldea. - New York: CRC PressTaylor \& Francis Group, 2013. - 635 p.

[11] Ryzhkov A. V. Analysis and selection of rational designs of a cylindrical linear motor with magnetoelectric excitation: $\mathrm{PhD}$ thesis : 05.09.01 /Voronezh, 2008. - 145 p. (In Russian).

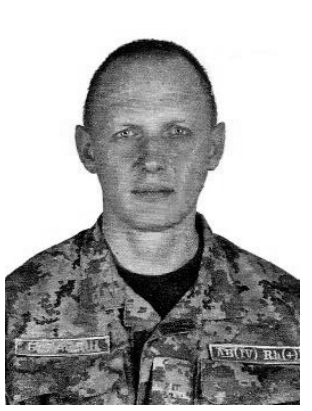

Maksim Balandin was born in 1976 in Lviv. In 1997 he has graduated from Odesa Institute of Ground Forces and obtained the specialty "Command Tactical Artillery". At present he is a postgraduate student (adjunct) of the scientific-organizational department of the Hetman Petro Sahaidachnyi National Army Academy. He has been involved in scientific work since 2008. The aspect of his research is increasing the energy independence of artillery units.

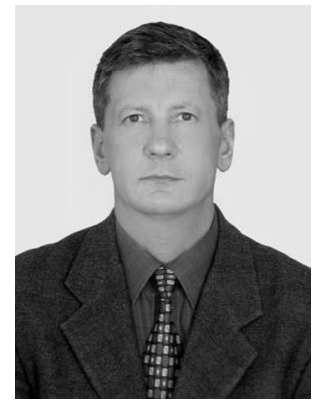

Atamanyuk Vitalii is a Professor of the Department of Electromechanics and Electronics at Hetman Petro Sahaidachnyi National Army Academy.

He graduated from Lviv Polytechnic Institute in 1982. He received $\mathrm{PhD}$ degree in 1992 from Moscow State Technical University named after N. Bauman in the field of radio location and navigation. He authored and co-authored more than 60 scientific publications. His scientific interests are concentrated in the field of scattering of radio waves by complex objects. 